\title{
Usability Considerations of Mobile Learning Applications
}

\author{
doi:10.3991/ijim.v3s1.854 \\ Ali Mostakhdemin-Hosseini \\ Helsinki University of Technology, ESPOO, Finland
}

\begin{abstract}
Mobile usability is not one-dimensional property of user interface, it has many components and attributes [1] The most attributes associated with the mobile usability are as following: Satisfaction, Efficiency, Learnability, Lack of Errors, and Memorability
\end{abstract}

The assessment and importance of the usability attributes varies based on the application and the type of the users. For the expert users' lack of errors, reliability and efficiency are important and for the novice users beside mentioned factors the adjustability, learnability and memorability are essentials factors. This paper reveals different usability considerations for mobile learning system with approparte guidelines.

Index Terms-Usability, Mobile Learning Content and Mobile Devices

\section{INTRODUCTION}

Based on ISO/FDIS definitions [2] usability is the extent to which a product can be used by specified users to achieve specified goals with effectiveness, efficiency and satisfaction in a specified context of use.

The overall components and the environments of mobile learning are presented on figure 1. The details descriptions of the major stakeholders are out of the scope of this paper. As figure 1 shows the mobile learning system / applications are very complex. At different level of design and development various stakeholders are involved. Having a usable mobile learning system and applications in such a complex environments requires extensive usability considerations and efforts.

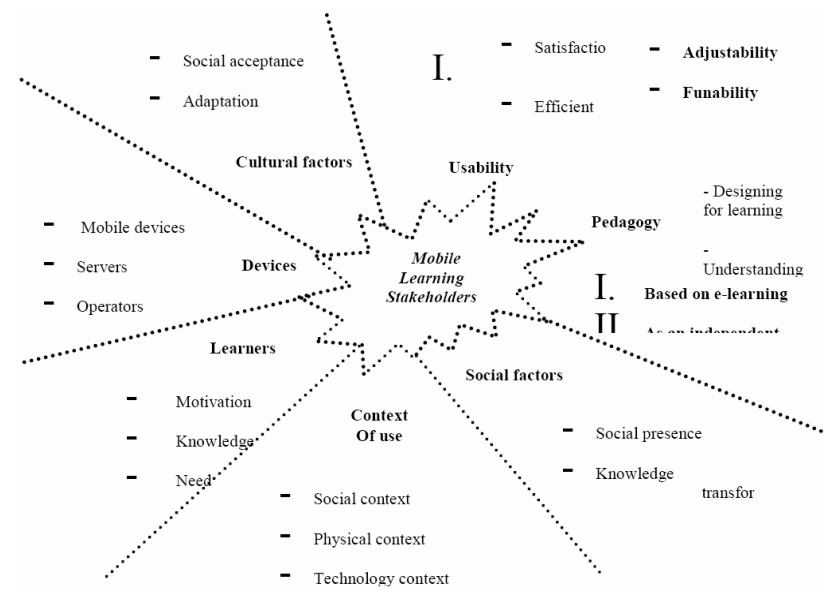

Figure 1. Mobile learning components and stakeholders.
Mobile learning as an independent platform consists of different stakeholders. These stakeholders independently and dependently play an important role in order to make a successful learning platform. It is essential to clarify the context of use of mobile learning platform, which enables to create a successful content. Mobile learning platform as an independent learning medium must be designed so that the social acceptance of the learning medium adapted easily by learners. Mobile devices manufactures and other service providers e.g. operators play the key role in mobile learning success. Having the mobile learning features and services enabled in the devices by manufactures assists the platform standardization and the social acceptance and adaptation by users. Mobile devices are capable to exchange multi-formatted data in fairly high speed nowadays. This advancement will overcome the lack of motivation due to slowness of the data retrieve, which risen during previous study. Based on the research [3] students in Finland have the knowledge and motivation to utilizing mobile learning system in their educational system. Having the mobile learning services in such a society as Finland is considered as needs and users expect to have this service in their mobile device.

\section{USABILITY CONSIDERATIONS OF MOBILE LEARNING}

As mobile devices become smarter and more complex which derived applications developers to design and provide more robust mobile learning applications and services. Usability considerations for such devices and applications become more important than before. Having a good user experiences for users is the target of all stakeholders. This study identifies three different usability stages for mobile learning system.

\section{A. Usability of the device}

New mobile devices with rich features and capabilities are complex to use and challenging for designing new applications. It is essentials to identify the mobile device components and define the usability criteria in order to have a good user experience. There has been extensive research and study on mobile device usage and usability e.g. Roto [4] reveals the latest study of mobile manufacture for design and develop usable devices for their target users. Betiol et al. [5] identified various mobile usability testing methods and revealed three evaluation approaches.

Following are examples of those components which reflect directly to have a good user experiences with mobile devices.

Keypad, even though the capabilities of the devices have improved but still a lot of mobile applications re- 
quires keypad as input medium for more users' convenience. For the simplicity and consistency the directional keys are integrated to keypad. Depends to the application each key can be used either as a function key or entering characters. As research [6] shows that the users are not happy with the keypad interface because it became more difficult as they keypad area is squeezed to make space for larger displays.

Displays, the smart mobile device functionalities require larger displays with high resolutions. Devices nowadays are capable to display motion picture, images and internet content.

Content Access, mobile users are always on the move. They use the devices more often on the move, so it is essential to have a quick access to contents and services on the device. The current content and services hieratical structures are not usable and efficient for on the move users.

UI style, the traditional mobile user interface and its format does not anymore respond with new heavy users of internet and PCs users. Mobile users have often more interactive and high structure user interface with PC and internet applications. This is also usability challenges that to increase the quality and quantity to give a similar user experience to vast amount of mobile users.

Battery lifetime

\section{B. Usability of the mobile application and mobile content}

The new devices are integrated with wide range of advanced technologies and othercapabilities such as sensors, images capturing and video camera. Designing and deploying new applications to mobile devices require extensive design consideration, due to the limitation in memory, screen size and processing power of the mobile devices. This may affect the usability of new applications in mobile devices. So usability assessment and evaluation of the mobile applications are highly recommended. Kaikkonen [7] revealed the importance of the usability tests and compared between the laboratory and field testing for mobile applications.

\section{Usability of the mobile service and mobile learning}

As Syvänen [8] argued mobile learning usability evaluation requires two different usability criteria. 1 . The physical usability based on Nielson usability criteria 2 . The pedagogical mobile usability with the criteria such as

- Leaner activity,

- Cooperative learning,

- Goal orientation,

- Applicability,

- Effectiveness and

- Valuation of previous knowledge

In addition to these criteria, this study also revealed the performance usability with the criteria such as

- efficiency,

- simplicity

- fast and easy to use

These criteria were identified during mobile learning proto-type testing [9].
Mobile device has important role for its user, this device not only has the communication medium role but also has the entertaining and personal tasks management role. The multi-role player device brings lots of challenges to the mobile application designer. In order to satisfy the user needs it is essential to define the usability goals before designing the application for the mobile devices. Mobile usability consists of many layers first the device usability layer which consists of the keys, displays, the device capability of application loading and the user interface style (physical usability)[12]. The second usability layer is related to the mobile applications itself (performance usability)[13]. The application usability consists of the application interaction facilities and navigation scheme of the applications.

New mobile learning usability attributes and components found during previous proto-types testing are as follows:

Adjustability: The degree to which a platform is acceptable as a learning platform by users with emphasis on the interaction style and the quality of the content of the platform

Funability: The m-learning platform and the concept pleased the users; the application has less uncertainty which does force users to quite the application as soon as possible.

Reliability: The m-learning platform shouldn't perform in unexpected ways.

Satisfaction: The user must feel that through mobile devices he/ she will be capable to perform their tasks with any external activities.

TABLE I.

EDUCATION COMPONENTS AND USABILITY FACTORS FOR MOBILE LEARNING

\begin{tabular}{|c|c|c|}
\hline $\begin{array}{c}\text { Com- } \\
\text { ponents }\end{array}$ & $\begin{array}{l}\text { Usability } \\
\text { Factors }\end{array}$ & Criteria \\
\hline \multirow{4}{*}{$\begin{array}{l}\text { Presen- } \\
\text { tation }\end{array}$} & Adjustability & $\begin{array}{l}\text { Supports as a learning medium / per- } \\
\text { sonalization }\end{array}$ \\
\hline & Funability & Facilities and acceptance of the tool \\
\hline & Reliability & $\begin{array}{l}\text { Supportive for communication, and } \\
\text { technology adequacy }\end{array}$ \\
\hline & Satisfaction & Perform the required task \\
\hline \multirow{4}{*}{$\begin{array}{l}\text { Activi- } \\
\text { ties }\end{array}$} & Adjustability & $\begin{array}{l}\text { Support the learner to perform the basic } \\
\text { learning activities }\end{array}$ \\
\hline & Funability & $\begin{array}{l}\text { Support the learner to perform tasks } \\
\text { without difficulties }\end{array}$ \\
\hline & Reliability & $\begin{array}{l}\text { Supports the learner to perform his task } \\
\text { securely }\end{array}$ \\
\hline & Satisfaction & $\begin{array}{l}\text { Successfully performed his educational } \\
\text { activities }\end{array}$ \\
\hline \multirow{4}{*}{$\begin{array}{c}\text { Com- } \\
\text { munica- } \\
\text { tions }\end{array}$} & Adjustability & $\begin{array}{l}\text { Supports the performance of basic } \\
\text { communication related tasks }\end{array}$ \\
\hline & Funability & Facilities and acceptance of the tool \\
\hline & Reliability & $\begin{array}{l}\text { Supportive for communication and } \\
\text { technology securely }\end{array}$ \\
\hline & Satisfaction & $\begin{array}{l}\text { Successfully performed his/ her task } \\
\text { securely }\end{array}$ \\
\hline \multirow{4}{*}{$\begin{array}{l}\text { Admini- } \\
\text { stration }\end{array}$} & Adjustability & Support the learners requirements \\
\hline & Funability & $\begin{array}{l}\text { Supportive for communication and } \\
\text { technology securely }\end{array}$ \\
\hline & Reliability & $\begin{array}{l}\text { Successfully performed his/her task } \\
\text { securely }\end{array}$ \\
\hline & Satisfaction & Successfully performed his/her tasks. \\
\hline
\end{tabular}


Usability criteria and guidelines [10] for m-learning platforms based on educational components [11] The usability factors and the measurement criteria for the mlearning platform based on educational components [11] are listed in table 1 . the mobile learning platform is reliable if the system is supportive for communication and its technology adequacy. Also the user satisfaction is based on the performance of the required task.

\section{CONCLUSION}

Usability and pedagogical factors play a very important role in m-learning. Mobile usability is a complex process and requires extensive efforts. Complexity in mobile devices and mobile contents requires different usability evaluation process. The usability of mobile devices, the usability of mobile content (pre installed applications by manufacture) and the usability of mobile learning system/ applications in the context of learning are important to consider. This paper reveals the usability features and criteria for m-learning based on education components were revealed.

\section{REFERENCES}

[1] Nielsen's Jakob 2003, http://www.useit.com/alertbox/20030825. $\underline{\mathrm{html}}$

[2] ISO/FDIS 17894, http://www.sname.org/committees/technical/sta ndards/ISOFDIS17894.pdf

[3] Attewell, J. and Savill-Smith, C. (2004) Learning with mobile devices - research and development - a book of papers. Learning Skills Development Agency: London.

[4] Roto Virpi, Developing Usable Mobile Phones, Nokia Research Center, Helsinki, Finland http://www.eurescom.de/message/mess ageDec2004/Developing usable_mobile_phones.asp

[5] Adriana Holtz Betiol, Walter de Areu Cybis, Usability Testing of Mobile Devices: A Comparison of three Approaches, https://www.se.auckland.ac.nz/courses/SOFTENG350/lectures/L5 \%20Usability\%20Mobile\%20Devices.pdf
[6] Farrugia Maria, (2006) "Future User Interface for Mobile Devices", Vodafone Group R\&D, UK, http://www.research. att.com/ rjana/MobEA-IV/PAPERS/MobEA_IV-Paper 8.pdf

[7] Keinonen T., Nieminen, M., Riihiaho. S, Säde. S (1996). Designing Usable Smart Products. Otaniemi, Finland. Helsinki University of Technology. TKO-C81 82 p. ISBN 951-22-3188-3"

[8] Syvänen Antti, Nokelainen Petri, Digitaalisen oppimateriaalin mobiilikäytettävyyden arvioinnin kriteerit, 2004, Saarinen Jorma (toim). 5/2004 Evaluator. Hämeenlinna: Hämeen AMK. 2004 http://www.uta.fi/hyper/projektit/mobile/pdf/eValuator chapter3.pdf

[9] Mostakhdemin-Hosseini Ali, Mustajärvi, Jari "Evaluation of Mobile Learning System Prototype", International association for development of Information Society, IADIS February 23-25th, 2005, Algarve, Portugal

[10] Melis Erica and, Weber Markus (2003), Lessons for (Pedagogic) Usability of eLearning Systems, http://www.ags.unisb.de/ melis/Pub/elearn03Usability.pdf

[11] Mostakhdemin-Hosseini Ali, Mustajärvi Jari, "Framework for Mobile-Learning System Based on Education Components", ICTAMI, International Conference on Theory and Applications of Mathematics and Informatics. October 24-26th,2003, Alba Iulia, Romania.

[12] Shari Trewin (2006), "Physical usability and the mobile web", ACM International Conference Proceeding series; VOL: 134. Proceedings of the 2006International cross-disciplinary workshop on Web accessibility (W4A): building the mobile web. Edinburgh, UK page 109-112

[13] Kekkonen Anne, Kallio Titti, Kekäläinen Aki, Kankainen Anu, Cankar Mihael, "Usability Testing of Mobile Applications A Comparison between Laboratory and field testing", Journal of Usability Studies, Issue 1. Vol November 2005, pp 4-16

\section{AUTHOR}

Ali. Mostakhdemin-Hossieni is a researcher at Helsinki University of Technology and senior lecturer at HAMK Applied Science University, Forssa, Finland (amir@cc.hut.fi).

This article was modified from a presentation at the International Conference on Interactive Mobile and Computer Aided Learning (IMCL2009) in Amman, Jordan, April 2009. Submitted, February 24, 2009. Published as resubmitted by the author(s) on July 20, 2009. 